\title{
SHORTNOTE
}

\section{SHEAR STRENGTH ESTIMATION MODEL FOR TROPICAL WOOD SPECIES}

\author{
Anderson Renato Vobornik Wolenski \\ Federal Institute of Santa Catarina \\ São Carlos, Brazil \\ Rodrigo Guerra Peixoto, Veronika Fedotova \\ Federal University of Minas Gerais \\ Belo Horizonte, Brazil \\ André Luís Christoforo \\ Federal University of São Carlos \\ São Carlos, Brazil \\ Francisco Antonio Rocco Lahr \\ University of São Paulo \\ São Carlos, Brazil \\ (Received February 20I8)
}

\begin{abstract}
For safety reasons, wood strength values are calculated based on their characteristic values. Brazilian national standard (NBR, in Portuguese "Norma Brasileira Regulamentadora") 7190 (1997) establishes ratios for characteristic strength estimation and three forms of wood characterization, with an emphasis on the simplified procedure for common species, which allows obtaining the strength characteristic values through equations correlating different mechanical properties. The present work evaluates the accuracy of the relation proposed by NBR 7190 (1997) of shear strength along the grain $\left(f_{\mathrm{v} 0, \mathrm{k}}\right)$ to compression strength along the grain $\left(f_{\mathrm{c} 0, \mathrm{k}}\right)\left(f_{\mathrm{v} 0, \mathrm{k}}=0.12 f_{\mathrm{c} 0, \mathrm{k}}\right)$. 960 experimental measurements of shear and compression strength values were performed for 40 hardwood species, and the precision of the relation proposed by the Brazilian standard was evaluated using the analysis of variance (ANOVA) method. Linear, exponential, logarithmic, and geometric regression models were used as an alternative to the NBR relation for shear strength estimation. The statistical analysis revealed that the geometric regression is the model of best fit.
\end{abstract}

KEYWORDS: Wood, strength properties, characteristic value, strength along the grain. 


\section{INTRODUCTION}

Timber structures have an elevated applicability potential in Brazil due to a vast number of wood species existing in the Amazonian rainforest. According to Steege et al. (2016), by 2015 there were already discovered more than 10000 wood species. This expressive number induces development of new research aiming at characterization of species that can potentially substitute those that already are commonly used in civil construction. Works of Mascia and Nicolas (2013), Silva et al. (2014), Segundinho et al. (2015), dos Reis et al. (2018) can be mentioned among other works that sought to investigate the species for structural purposes.

In Brazil, the standard NBR 7190 (1997) regulates the use of timber for structural needs, establishing the requirements for project development, construction and control of wooden structures, based on probabilistic methods, which assess fracture strength, instability, excessive deformation, and durability of the structure. The standard also specifies the complete, minimal and simplified characterization methods of wood physical and mechanical properties. According to Almeida et al. (2017), such characterization is justified by anatomic structure of wood, distinct for each species, and loading type, grain direction and moisture content shall be taken into account.

Hence, it is of great importance to examine the equations that estimate the mechanical properties of the species used in construction. Such equations are established in the standard NBR 7190 (1997, p. 15) defining the simplified characterization method, which allows obtaining different strength properties of common wood species when experimental data are not available.

However, Logsdon et al. (2010) stress that this simplified method should not be the only rule for determination of characteristic wood properties. These authors sought to benchmark a model for characteristic compression strength $\left(f_{\mathrm{c} 0, \mathrm{k}}\right)$ estimation, aiming to obtain a more appropriate statistical model for Dinizia excelsa Ducke species. They have concluded that NBR equation is more conservative as it provides slightly lower $f_{\mathrm{c} 0, \mathrm{k}}$ values.

Similarly to the previous study, Matos and Molina (2016) investigated a correlation between compression and shear strength $\left(f_{\mathrm{v} 0, \mathrm{k}}\right.$ and $\left.f_{\mathrm{c} 0, \mathrm{k}}\right)$ of Pinus elliotti and Corymbia citriodora species, comparing an experimental relation with the standardized relations of NBR 7190 (1997) and ISO 1391 (2005), and concluded that the values obtained from relations of the Brazilian standard were superior to those of the European standard for both species. Krajewski et al. (2016) compared shear strength along the grain of 16-18th century Pinus sylvestris L. heartwood from Central Poland and that of modern wood, and found that the aged wood had better technical quality.

Other authors also investigated some of the hardwood species that are studied in the present work, focusing on physical and mechanical properties for distinct sites: Apuleia leiocarpa (Soriano et al. 2015), Goupia glabra Aubl. (Silva et al. 2018), and Cedrela odorata (Tenorio et al. 2018).

Previous studies demonstrate the importance of assessing physical and mechanical properties of wood in order to obtain reliable and safe estimates for structural dimensioning. Therefore, there is a notable relevance of research seeking equations that estimate mechanical properties of different species for structural use. A need for such estimates motivated the present work, in which 40 species of dicot woods were assessed. NBR 7190 (1997, p. 90, Appendix E) presents average values of physical and mechanical properties of 43 species of native and afforestation woods, and this list of species is similar to the species evaluated in the present study, thus reinforcing the reliability of the statistical analyses carried out here exclusively for woods of native Brazilian forests. 


\section{MATERIALS AND METHODS}

As required by NBR 7190 (1997), homogeneous batches were used in all the tests, with the batch volume not exceeding $12 \mathrm{~m}^{3}$, and specimens randomly extracted, limited to one sample per beam, as shown on Fig. 1 . In order to carry out the tests, all wood species were stored at $12 \%$ moisture level, which corresponds to equilibrium moisture content as defined by this standard. All the tests were performed at the LaMEM (in Portuguese Laboratório de Madeiras e Estruturas de Madeira) of the University of São Paulo (USP), following the procedures described in Appendix B of NBR 7190 (1997). 12 samples of each species were tested, giving a total of 960 experimental values of shear $\left(f_{\mathrm{V} 0}\right)$ and compressive $\left(f_{\mathrm{c} 0}\right)$ strengths parallel to the grain (Fig. 1, Tab. 1).

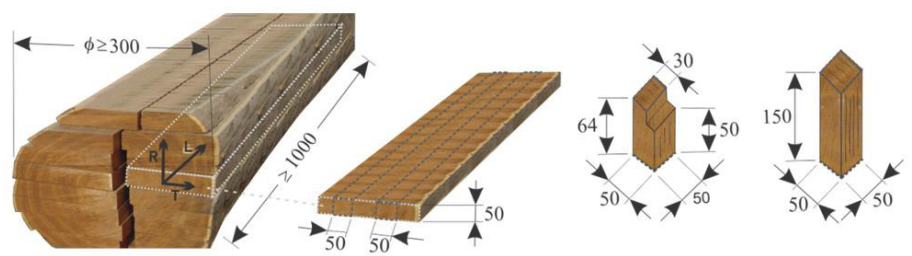

Fig. 1: Extraction scheme and dimensions (in $\mathrm{mm}$ ) of the specimens for compressive and shear tests.

In order to validate the equation given in NBR 7190 (1997):

$$
f_{\mathrm{v} 0, \mathrm{k}}=0.12 \cdot f_{\mathrm{c} 0, \mathrm{k}} \quad(\mathrm{MPa})
$$

Thus, these properties $\left(f_{\mathrm{v} 0, \mathrm{k}} / f_{\mathrm{c} 0, \mathrm{k}}\right)$ were determined following the simplified procedure described in NBR 7190 (1997). It should be emphasized that Eq. 1 is only applicable for characterization of commonly used species in cases when experimental data from complete characterization are not available. The simplification found in Eq. 1 may or may not be consistent with actual results of experimental analyzes.

Alternatively, this research sought to evaluate an applicability of regression models for estimation of mechanical parameters $\left(f_{\mathrm{v} 0, \mathrm{k}}\right.$ from $\left.f_{\mathrm{c} 0, \mathrm{k}}\right)$. Experimentally obtained strength values were fit into Eqs. 2 to 5 to verify if any of the regression models (linear, exponential, logarithmic or geometric) can be used for wood strength estimation.

$$
\begin{aligned}
& Y=a+b \cdot X \quad \text { (linear) } \\
& Y=a \cdot e^{b} \cdot X \quad \text { (exponential) } \\
& Y=a+b \cdot \ln (X) \quad \text { (logarithmic) } \\
& Y=a \cdot X^{b} \quad \text { (geometric) }
\end{aligned}
$$

where: $\quad Y(\mathrm{MPa})$ - a dependent variable, $X(\mathrm{MPa})$ - an independent variable, $a$ and $b$ (dimensionless) - parameters of the model, obtained by the least squares method.

The analysis of variance (ANOVA) was used to determine the equivalence of strength values estimated by the models and those experimentally obtained (with the significance level set to 0.05). The coefficient of determination $\left(\mathrm{R}^{2}\right)$ was used to determine the regression model of best fit. 


\section{RESULTS AND DISCUSSION}

Tab. 1 shows experimentally obtained compression and shear strength values for 40 species of hardwood. Comparison of the values presented in Tab. 1 with the values found in Appendix E of NBR 7190 (1997) demonstrates agreement of experimental results with those already registered.

Tab. 1: Strength values (MPa) for 40 species of hardwood.

\begin{tabular}{|c|c|c|c|c|c|c|c|}
\hline \multirow{2}{*}{ Wood Species ${ }^{1}$} & \multicolumn{2}{|c|}{ Experimental values } & \multirow{2}{*}{$\begin{array}{c}f_{\mathrm{v} 0, \mathbf{k}} \\
\text { (Eq. 1) }\end{array}$} & \multirow{2}{*}{ Wood species ${ }^{1}$} & \multicolumn{2}{|c|}{ Experimental values } & \multirow{2}{*}{$\begin{array}{c}f_{\mathrm{v} \mathbf{0}, \mathbf{k}} \\
(\mathrm{Eq} .1)\end{array}$} \\
\hline & $f_{\mathrm{c} 0, \mathrm{k}}$ & $f_{\mathrm{v} 0, \mathrm{k}}$ & & & $f_{\mathrm{c} 0, \mathrm{k}}$ & $f_{\mathrm{v} 0, \mathrm{k}}$ & \\
\hline Vatairea cf. guianensis & 51.06 & 12.10 & 6.13 & Micropholis venulosa & 90.41 & 17.39 & 10.84 \\
\hline Dinizia excelsa & 72.73 & 13.35 & 8.73 & Peltophorum dubium & 56.34 & 17.47 & 6.76 \\
\hline Parkia cf. pendula & 41.87 & 12.72 & 5.02 & Mezilaurus itauba & 68.44 & 16.32 & 8.21 \\
\hline Anadenanthera colubrina & 55.55 & 17.95 & 6.67 & Hymenaea courbaril & 89.96 & 23.08 & 10.80 \\
\hline Sebastiania commersoniana & 45.58 & 13.75 & 5.47 & Ocotea neesiana & 50.60 & 10.40 & 6.07 \\
\hline Andira anthelmia & 40.50 & 6.64 & 4.86 & Sextonia cf. rubra & 49.14 & 9.77 & 5.90 \\
\hline Erisma cf. fuscum & 27.30 & 11.62 & 3.28 & Manilkara cf. inundata & 79.46 & 20.77 & 9.54 \\
\hline Cassia ferruginea & 36.37 & 12.97 & 4.36 & Qualea paraensis & 61.53 & 14.34 & 7.38 \\
\hline Bertholletia excelsa & 38.93 & 7.04 & 4.67 & Clarisia racemosa & 62.41 & 15.18 & 7.49 \\
\hline Calycophyllum multiflorum & 54.54 & 15.55 & 6.54 & Pradosiasp. & 72.34 & 14.63 & 8.68 \\
\hline Calophyllum longifolium & 50.91 & 12.30 & 6.11 & Parinari excelsa & 55.22 & 12.01 & 6.63 \\
\hline Cedrela odorata & 33.18 & 8.56 & 3.98 & Copaifera langsdorffii & 45.06 & 10.62 & 5.41 \\
\hline Cedrela cf. fissilis & 29.99 & 7.13 & 3.60 & Tapirira sp. & 43.74 & 12.39 & 5.25 \\
\hline Cedrelinga cateniformis & 29.06 & 8.37 & 3.49 & Erisma uncinatum & 27.20 & 6.70 & 3.26 \\
\hline Dipteryx odorata & 96.16 & 13.51 & 11.54 & Geissospermum sericeum & 61.60 & 11.37 & 7.39 \\
\hline Copaifera multijuga & 44.13 & 10.25 & 5.30 & Vochysia haenkeana & 44.79 & 9.30 & 5.38 \\
\hline Goupia paraensis & 55.28 & 12.63 & 6.63 & Diplotropis sp. & 93.02 & 17.42 & 11.16 \\
\hline Apuleia leiocarpa & 65.36 & 16.28 & 7.84 & Tachigali glauca & 75.46 & 14.54 & 9.06 \\
\hline Planchonella pachycarpa & 43.10 & 12.14 & 5.17 & Bagassa guianensis & 59.84 & 19.18 & 7.18 \\
\hline Luetzelburgia cf. guaissara & 58.92 & 17.51 & 7.07 & Ruizterania retusa & 51.28 & 9.83 & 6.15 \\
\hline
\end{tabular}

*Brazilian Flora 2020 in construction, Rio de Janeiro Botanical Garden, Brazil.

40 experimentally obtained results of $f_{\mathrm{v} 0, \mathrm{k}}$ (Tab. 1 , middle column) were compared to $f_{\mathrm{v} 0, \mathrm{k}}$ $(\mathrm{MPa})$ values calculated from experimental $f_{\mathrm{c} 0, \mathrm{k}}(\mathrm{MPa})$ values (Tab. 1, left column) using Eq. 1 (Tab. 1, right column) and ANOVA. The Tab. 2 and Fig. 2 show the result of the analysis.

Tab. 2: Results of ANOVA for the sample sets: $f_{v 0, k}$ (experimental values) and $f_{v 0, k}(E q .1)$.

\begin{tabular}{|c|c|c|c|c|c|}
\hline Source & $\mathbf{D F}$ & $\mathbf{S S}_{\mathrm{aj}}$ & $\mathbf{M S}_{\mathbf{a j}}$ & F-Value & P-Value \\
\hline $\begin{array}{c}\text { Condition } \\
\left(f_{\mathrm{v} 0, \mathrm{k}}=0.12 \cdot f_{\mathrm{c} 0, \mathrm{k}}\right)\end{array}$ & 1 & 814.4 & 814.39 & 78.01 & 0.000 \\
\hline Error & 78 & 814.0 & 10.44 & -- & -- \\
\hline Total & 79 & 1628.6 & -- & -- & -- \\
\hline
\end{tabular}

* DF - Degrees of Freedom; $\mathbf{S S}_{\mathbf{a j}}$ - sum of squares; $\mathbf{M S}_{\mathbf{a j}}$ - mean squares. 


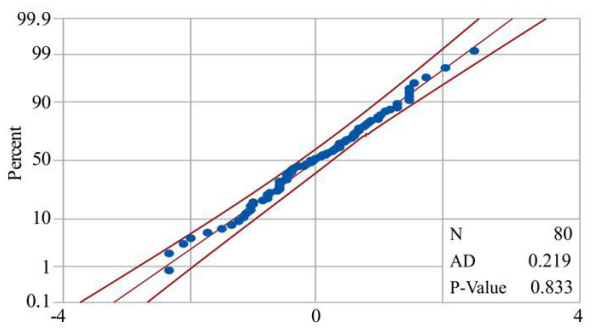

Fig. 2: Probability plot for transformed data for condition: $f_{v 0, k}=0.12 \cdot f_{c 0, k}$.

It can be seen that the compared groups of values are not equivalent (P-Value $=0.000$, Tab. 2), indicating an inexactness of Eq. 1 proposed by NBR 7190 (1997). The Fig. 2 confirms the results of ANOVA, for a normal distribution of data and by P-Value $=0.833$.

Alternatively, the Tab. 3 and Fig. 3 present regression models for estimation of $f_{\mathrm{v} 0, \mathrm{k}}(\mathrm{MPa})$ values from $f_{\mathrm{c} 0, \mathrm{k}}(\mathrm{MPa})$ values for 40 examined wood species. P-value allows evaluating the applicability $(\mathrm{P}<0.05)$ or non-applicability $(\mathrm{P}>0.05)$ of the regression model.

Tab. 3: Regression models for estimation of $f_{v 0, k}$ from $f_{c 0, k}$.

\begin{tabular}{|l|c|c|c|c|c|}
\hline \multicolumn{1}{|c|}{ Model } & Equation & $\boldsymbol{a}$ & $\boldsymbol{b}$ & P-value & $\mathbf{R}^{\mathbf{2}} \mathbf{( \% )}$ \\
\hline Linear & $f_{\mathrm{v} 0, \mathrm{k}}=\mathrm{a}+\mathrm{b} \cdot\left(f_{\mathrm{c} 0, \mathrm{k}}\right)$ & 4.34 & 0.16 & 0.000 & 53.53 \\
\hline Exponential & $f_{\mathrm{v} 0, \mathrm{k}}=\mathrm{a} \cdot \mathrm{e} \mathrm{b} \cdot(f \mathrm{c} 0, \mathrm{k})$ & 6.27 & 0.01 & 0.000 & 53.01 \\
\hline Logarithmic & $f_{\mathrm{v} 0, \mathrm{k}}=\mathrm{a}+\mathrm{b} \cdot \ln \left(f_{\mathrm{c} 0, \mathrm{k}}\right)$ & -21.71 & 8.80 & 0.000 & 55.24 \\
\hline Geometric & $f_{\mathrm{v} 0, \mathrm{k}}=\mathrm{a} \cdot f_{\mathrm{c} 0, \mathrm{k}}$ & 0.76 & 0.71 & 0.000 & 56.89 \\
\hline
\end{tabular}
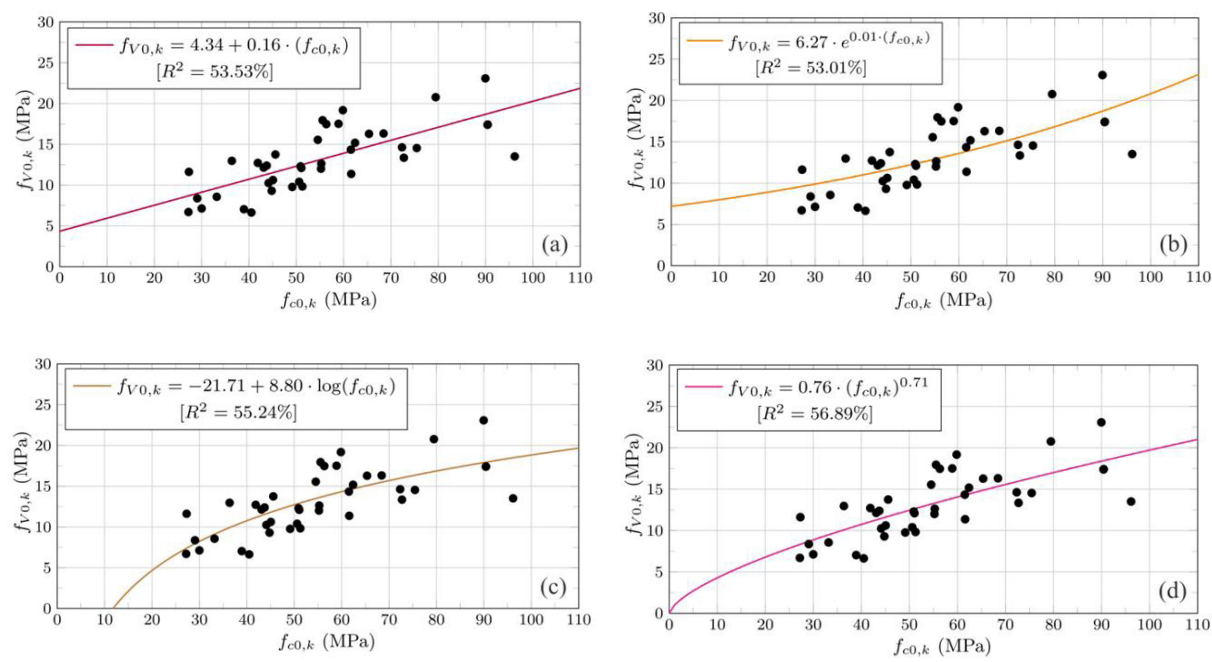

Fig. 3: Regression models for shear strength: Linear (a), Exponential (b), Logarithmic (c), and Geometric (d). 
The present study expanding the number of studied species for the total of 40 hardwood species. This large sample supports a validity of the equation $f_{\mathrm{v} 0, \mathrm{k}}=0.76 \cdot\left(f_{\mathrm{c} 0, \mathrm{k}}\right)^{0.71}(\mathrm{MPa})$ (Fig. $3 \mathrm{~d}$ ) as the most adequate for estimation of shear strength from compression strength for native Brazilian species, which lack a complete physical and mechanical characterization.

\section{CONCLUSIONS}

Mechanical properties of 40 wood species were experimentally determined, and the obtained values were in accordance with those found in the literature (NBR 7190, 1997). Comparison of shear strength values obtained experimentally and calculated using the Eq. $1\left(f_{\mathrm{v} 0, \mathrm{k}}=0.12 \cdot f_{\mathrm{c} 0, \mathrm{k}}\right)$ demonstrated a significant difference between the compared groups, indicating weakness of the equation proposed by NBR 7190 (1997).

The regression models proposed in this work (Tab. 3 and Fig. 3) are an alternative to the equation of the standard. The higher coefficient of determination $\left(\mathrm{R}^{2}=52.89 \%\right)$ was found for the geometric model, suggesting that it is the model of best fit, $f_{\mathrm{v} 0, \mathrm{k}}=0.76 \cdot\left(f_{\mathrm{c} 0, \mathrm{k}}\right){ }^{0.71}(\mathrm{MPa})$, and is the most appropriate for estimation of shear strength along the grain from compression strength values. The analyzed tropical wood species, classified as Brazilian hardwood, demonstrate a potential for structural use in civil engineering.

\section{REFERENCES}

1. Almeida, T.H., Almeida, D.H., Araújo, V.A., Silva, S.A.M., Christoforo, A.L., Lahr, F.A.R, 2017: Density as estimator of dimensional stability quantities of Brazilian tropical woods. BioResources 12 (3): 6579-6590.

2. Dos Reis, P.C.M., Souza, A.L., Reis, L.P., Carvalho, A.M.M.L., Mazzei, L., Rêgo, L.J.S., Leite, H.G., 2018: Artificial neural networks to estimate the physical-mechanical properties of Amazon second cutting cycle wood. Maderas. Ciencia y Tecnología 20 (1): 343-352.

3. ISO 13910, 2005: Structural timber - characteristic values of strength-graded timber sampling, full-size testing and evaluation.

4. Krajewski, A., Kozakiewicz, P., Witomski, P., 2016: Shear strength of scots pine (Pinus sylvestris L.) from the historical buildings. Wood Research 61 (5): 845-850.

5. Logsdon, N.B., De Jesus, J.H., Penna, J.E., 2010: Evaluation of the estimators of the characteristic strength to compression parallel to the grain. Scientia Forestalis 38 (1): 579-587.

6. Mascia, N.T., Nicolas, E.A., 2013: Determination of Poisson's ratios in relation to fiber angle of a tropical wood species. Construction and Building Materials 41 (4): 691-696.

7. Matos, G.S., Molina, J.C., 2016: Shear strength of wood in direction parallel to the grain according to the standards ABNT NBR 7190: 1997 and ISO 13910: 2005. Revista Matéria 21 (4): 1069-1079.

8. NBR 7190, 1997: Design of wooden structures. Rio de Janeiro, Brazil, 107 pp.

9. Segundinho, P.G.A., Lahr, F.A.R., Regazzi, A.J., Carreira, M.R., 2015: Variation of modulus of elasticity obtained through the static bending method considering the $\mathrm{S} / \mathrm{h}$ ratio. Wood Research 60 (2): 189-200.

10. Silva, F., Higuchi, N., Matos, J.M., Paula, E.M., Santos, J., 2014: Nondestructive evaluation of hardness in tropical wood. Journal of Tropical Forest Science 26 (1): 69-74. 
11. Silva, C.E.G, Almeida, D.H., Almeida, T.H., Chahud, E., Branco, L.A.M.N., Campos, C.I., Lahr, F.A.R, Christoforo, A.L., 2018: Influence of the procurement site on physical and mechanical properties of Cupiúba wood species. BioResources 13 (2): 4118-4131.

12. Soriano, J., Veiga, N.S., Martins, I.Z., 2015: Wood density estimation using the sclerometric method. European Journal of Wood and Wood Products 73 (1): 753-758.

13. Steege, H., Vaessen, R.W., López, D.C., Sabatier, D., Antonelli, A., Oliveira, S.M.; Pitman, N.C.A., Jørgensen, P.M., Salomão, R.P., 2016: The discovery of the Amazonian tree flora with an update checklist of all known tree taxa. Scientific Reports 6 (1): 1-15.

14. Tenorio, C., Moya, R., 2018: Evaluation of wood properties of four ages of Cedrela odorata trees growing in agroforestry systems with Theobroma cacao in Costa Rica. Agroforestry Systems 1 (1): 1-16.

Anderson Renato Vobornik Wolenski*

Federal Institute of Santa Catarina

Department of Civil Engineering

Avenida Aloísio Stoffel, i27i, Cep 89885-00o

São Carlos, Sc, Brazil

*Corresponding author: anderson.wolenski@ifsc.edu.br

\author{
Rodrigo Guerra Peixoto, Veronika Fedotova \\ Federal University of Minas Gerais \\ Department of Structural Engineering \\ Avenida Antonio Carlos, 6627, Cep 31270-90i \\ Belo Horizonte, Mg, Brazil \\ André Luís Christoforo \\ Federal University of São Carlos \\ Department of Civil Engineering \\ Rodovia Washington Luís, Cep I3565-905 \\ São Carlos, Sp, Brazil \\ Francisco Antonio Rocco Lahr \\ University of São Paulo \\ Department of Structural Engineering \\ Avenida Trabalhador São-Carlense, 400, Cep i3566-590 \\ São Carlos, Sp, Brazil
}


